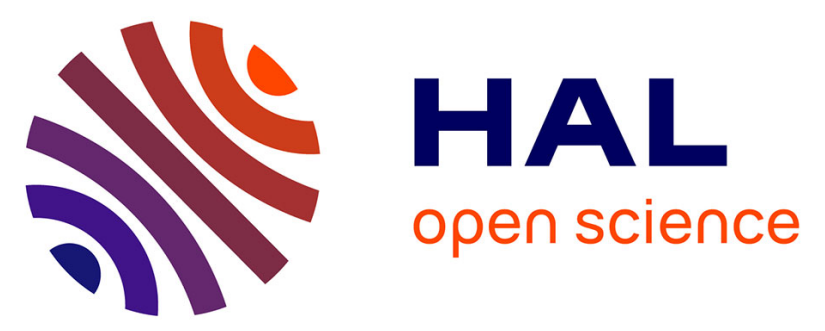

\title{
TAO2000 V2 computer-assisted force feedback telemanipulators used as maintenance and production tools at the AREVA NC-La Hague fuel recycling plant
}

Franck Geffard, Philippe Garrec, Gérard Piolain, Marie-Anne Brudieu, Jean-François Thro, Alain Coudray, Eric Lelann

\section{To cite this version:}

Franck Geffard, Philippe Garrec, Gérard Piolain, Marie-Anne Brudieu, Jean-François Thro, et al.. TAO2000 V2 computer-assisted force feedback telemanipulators used as maintenance and production tools at the AREVA NC-La Hague fuel recycling plant. Journal of Field Robotics, 2012, 29, pp.161 174. $10.1002 /$ rob.20426 . cea-01592595

\section{HAL Id: cea-01592595 \\ https://hal-cea.archives-ouvertes.fr/cea-01592595}

Submitted on 25 Sep 2017

HAL is a multi-disciplinary open access archive for the deposit and dissemination of scientific research documents, whether they are published or not. The documents may come from teaching and research institutions in France or abroad, or from public or private research centers.
L'archive ouverte pluridisciplinaire HAL, est destinée au dépôt et à la diffusion de documents scientifiques de niveau recherche, publiés ou non, émanant des établissements d'enseignement et de recherche français ou étrangers, des laboratoires publics ou privés. 


\title{
TAO2000 V2 Computer-Assisted Force Feedback Telemanipulators Used as Maintenance and Production Tools at the AREVA NC-La Hague Fuel Recycling Plant
}

\author{
Franck Geffard and Philippe Garrec \\ Interactive Robotics Laboratory, CEA, LIST, F-92265, Fontenay aux Roses, France \\ e-mail:franck.geffard@cea.fr, philippe.garrec@cea.fr \\ Gérard Piolain \\ Maintenance Department, AREVA NC-La Hague Plant, F-50440, Beaumont-Hague, France \\ e-mail: gerard.piolain@areva.com
}

Marie-Anne Brudieu and Jean-François Thro

Recycling Business Unit, AREVA, La Defense, F-92084, Paris, France

e-mail: marie-anne.brudieu@areva.com, jean-francois.thro@areva.com

Alain Coudray and Eric Lelann

Robotics Department, AREVA EEP/MECACHIMIE, F-50440, Beaumont-Hague, France

e-mail: alain.coudray@areva.com,eric.lelann@areva.com

Received 1 March 2011; accepted 6 September 2011

During a 15-year joint research program, French Atomic Energy Agency Interactive Robotics Laboratory (CEA LIST) and AREVA have developed several remote operation devices, also called telerobots. Some of them are now commonly used for maintenance operations at the AREVA NC (Nuclear Cycle)-La Hague reprocessing plant. Since the first maintenance operation in 2005, several other successful interventions have been realized using the industrial MA23/RX170 telemanipulation system. Moreover, since 2010, the through-the-wall telerobot named MT200 TAO based on the slave arm of the MSM MT200 (La Calhène ${ }^{\mathrm{TM}}$ ), has been evaluated in an active production cell at the AREVA NC-La Hague fuel recycling plant. Although these evaluations are ongoing, the positive results obtained have led to an update and industrialization program. All these developments are based on the same generic control platform, called TAO2000 V2. TAO2000 V2 is the second release of the CEA LIST core software platform dedicated to computer aided force-feedback teleoperation (TAO is the French acronym for computer aided teleoperation). This paper presents all these developments resulting from the joint research program CEA LIST/AREVA. The TAO2000 V2 controller is first detailed, and then two maintenance operations using the industrial robot RX170 are presented: the removal of the nuclear fuel dissolver wheel rollers and the cleanup of the dissolver wheel interbucket spaces. Finally, the new MT200 TAO system and its evaluations at the AREVA NC-La Hague facilities are discussed. (c) 2011 Wiley Periodicals, Inc.

\section{INTRODUCTION}

In nuclear fuel cycle facilities, such as fuel manufacturing and recycling plants, nuclear power plants, and interim waste storage sites, materials handling, preventive or corrective maintenance, and cleanup or dismantling must often be carried out remotely due to the dose environment. Telerobotics and remote handling $(\mathrm{RH})$ technologies aim at improving operator working conditions with respect to the ALARA principle (radiological protection optimization of the workers exposed to ionizing radiation, which says that exposure must be kept As Low As Reasonably Achievable). These technologies also aim at providing strong reliability as well as higher safety and efficiency during the operations.
Fifteen years ago, the French Atomic Energy Agency Interactive Robotics Laboratory (CEA LIST) and AREVA started an ambitious research and development (R\&D) program in robotics and $\mathrm{RH}$ technologies applied to spentfuel management facilities in France, in order to cover the requirements of the different plant life cycles. CEA LIST is in charge of the conceptual studies, as well as of the development of the prototypes, and AREVA is in charge of the specifications and of the industrialization of the developments.

Robotic developments at AREVA are applied to plants in decommission, as well as to operating plants, in particular production plants, for carrier systems, for welding and contamination checking, and for repairing, inspecting, or cleaning up. Robotics intervention systems can be mounted

Journal of Field Robotics 29(1), 161-174 (2012) (c) 2011 Wiley Periodicals, Inc

View this article online at wileyonlinelibrary.com • DOI: 10.1002/rob.20426 

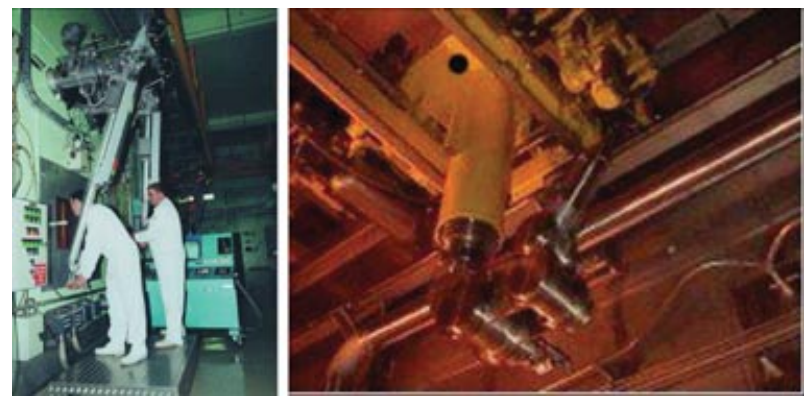

Figure 1. AREVA NC robotic technologies: Workstation (left) and mobile (right).

either through the wall or on vehicles to fit different types of hot cells (see Figure 1).

Development carried out by CEA LIST and AREVA has focused on technological components that can be used in different types of systems. The central concept is the force feedback operating mode, also called TAO (French acronym for computer aided teleoperations). It allows a distant operating person to feel the strength exerted by the slave arm or robot. This technology is implemented though "TAO2000," a software platform dedicated to computer-aided teleoperation (Gicquel, Andriot, Coulon-Lauture, Measson, \& Desbats, 2001), and the telerobotics systems using motorized robots as master and slave arms, designed and qualified to respond to the AREVA NC-La Hague hot cells constraints and needs (Piolain et al., 2010).

Robotics systems can use either off-the-shelf industrial robots or devices specifically designed for teleoperations:

Industrial arms (modified off-the-shelf robots): The most common model used at the La Hague is the RX170 (Stäubli ${ }^{\mathrm{TM}}$ robot) that has been rad-hardened and its backdrivability enhanced in order to be used as a part of a force-feedback telemanipulation system. The industrial integration of these systems is carried out by MECACHIMIE, a subsidiary of AREVA. MECACHIMIE now proposes the MA23/RX170 telerobotic system for several maintenance operations at the AREVA spentfuel management facilities in France in order to address the needs and requirements of the different plant life cycles. Industrial integration included modifications of the hardware and software of each new robot, validation tests, preparation of the whole procedure, and training the operators. Two major types of maintenance operations realized with this system over the past 5 years are presented in this paper. The first one, the removal of the rollers of the nuclear fuel dissolver wheel, was realized for the first time in 2005 and has since been reproduced two times. The second one is the clean up of the dissolver wheel interbucket spaces, a more complicated case.
Dedicated arms: This second category of telerobotic systems corresponds to arms that have been specifically designed for force-feedback operations in highly radioactive environments. Two representative systems in this category are the redundant arm called "dexterous arm" (Desbats et al., 1999) and the MT200 TAO (Garrec, Piolain, Lamy-Perbal, \& Friconneau, 2005). The MT200 TAO is a through-wall telescopic computer aided teleoperation (TAO) system using the slave arm of a MT200 MSM. It is functionally equivalent to the MT200 wall-transmission mechanical master-slave manipulator (MSM) and uses the same standard wall transmission. The first successful evaluation of the system was carried out for 10 months on a daily basis in a production cell at the AREVA NC-La Hague facilities. This system is detailed in this paper.

All these developments use the same controller, TAO2000 V2. Primarily designed to control force-feedback telemanipulation systems, TAO2000 V2 also integrates hybrid modes (force/position control laws) and preprogrammed trajectories (robotic control laws). Robotics control laws offered by some other industrial controllers, via a proprietary API, can sometimes be preferred and used within the TAO2000 V2 context. This software platform is detailed in the next section.

\section{TAO2000 V2 SOFTWARE PLATFORM}

TAO2000 ${ }^{1}$ is a core software platform dedicated to computer-aided force-feedback teleoperation. TAO2000 has been developed by the CEA LIST as a generic masterslave force feedback teleoperation system able to control different types of manipulators (Garrec, Friconneau, \& Louveau, 2004; Gicquel et al., 2001) (Figure 2). Similar to many other middleware, most of the TAO2000's parts are reusable components (object-oriented C). Nevertheless, comparison with other famous middlewares such as Orocos (Bruyninckx, 2001) or ROS ends here. TAO2000 is an end user-oriented system, with a well-defined set of features, including control and graphical user interface (GUI) capabilities. Although some robotics modes are available and are frequently used during tasks, TAO2000 is dedicated to force-feedback telemanipulation. It allows high-speed synchronization between several real and virtual mechanisms (master arm, slave arm, camera, dynamic simulation engine, etc.).

By "genericity," we understand that once hardware $\mathrm{I} / \mathrm{O}$ problems are solved, a new robot type can be integrated in a few days. Thus any combination of already existing robots can be devised for a specific application

${ }^{1}$ In "TAO2000," "TAO" is a French acronym for "computer-aided teleoperation" (CAT). 


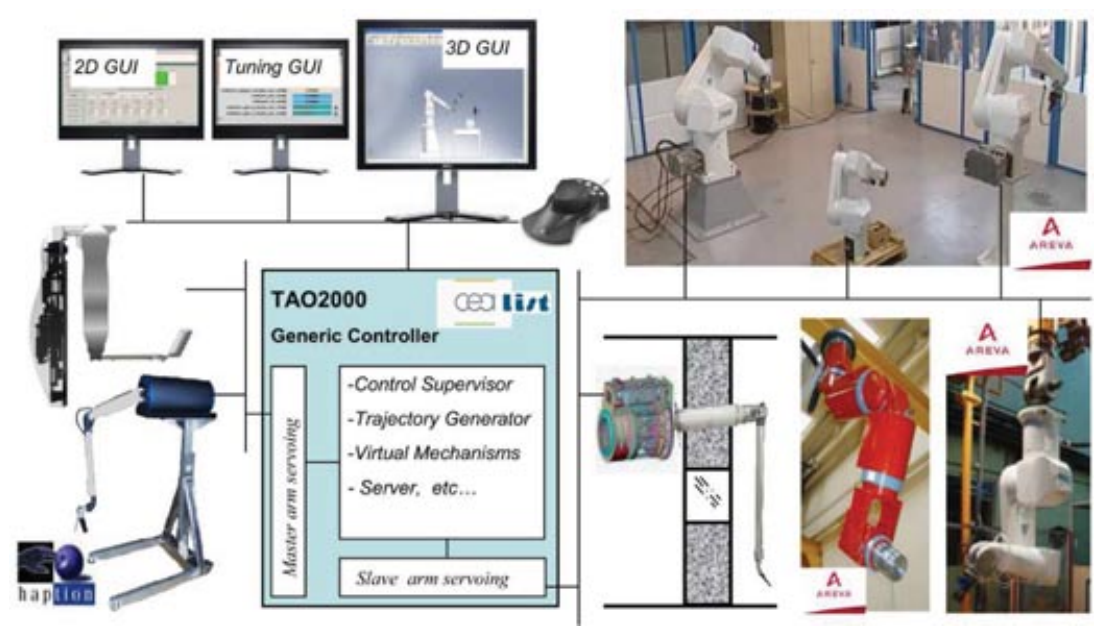

Figure 2. TAO2000 controller software architecture.

only by modifying some configuration files. These capabilities have been proved with a large variety of telerobots (Desbats \& Piolain, 2005). "Portability" relies directly on the selected operating system. For example, using VxWorks ${ }^{\mathrm{TM}}$, the same code is running on a PowerPc VME-based controller (Stäubli ${ }^{\mathrm{TM}} \mathrm{RX} 170$ ) and on an X86-based industrial PC controller (Haption ${ }^{\mathrm{TM}}$ Virutose 6D).

\subsection{Multirobots, Multiclients}

The TAO2000 controller is implemented with no hardcoded limitation on the number of robots synchronously controlled (limitation comes only from computing and communication performances). This allows two kinds of cooperation between the controlled mechanisms. First, a robot base frame may be referenced to another robot terminal frame at each time stamp (usually around $2 \mathrm{~ms}$ ). This allows, for example, the control of a robot on a mobile stand. Second, two (or more) robots, real or virtual, can be combined in order to implement the force-feedback teleoperation feature.

The TAO2000 controller is also multiclient. This allows the connection of several GUI, ranging from the tuning interface to the three-dimensional (3D) graphical interface, as well as, for example, a SpaceMouse ${ }^{\mathrm{TM}}$. The communication between the subsystems is grounded on a client-server model in which the controller is the telerobotics server. This model is implemented by a C/C++ library called TaoLib, also available in Python and $\mathrm{Tcl}$ languages.

\subsection{TAO2000 Control Modes}

TAO2000 is a multimechanism robotics and telerobotics controller software and can therefore control syn- chronously several robots. This provides masters and slaves with full-force feedback manual modes, but also, typically, slaves with full automatic modes (position and speed control), shared manual/automatic modes, and hybrid position/force control modes.

Control laws are implemented either in joint space or in Cartesian space. As special attention has been paid to deal with compliant and noncompliant mode switching, the operator can commute spaces and modes during a task. Cartesian space control laws allow the force feedback coupling of nonhomothetic manipulators. For example, a seven-joint orthetic arm can be coupled with a six-joint industrial robot (Figure 2).

An advanced feature uses virtual mechanism, hence facilitating hybrid force/position task specification and execution by the end user. This concept has been fully described in Joly and Andriot (1994). It allows the operator to constraint his movements. For example, using a prismatic virtual mechanism to drill a hole ensures that the bit keeps its orientation. The hole is then well made, and the risk of breaking the bit is limited. In the TAO2000 V2 controller, there are two ways of sharing a tripartite force reflecting coupling between a master, a slave, and a virtual mechanism:

- By using the local virtual mechanism. In the controller, several basic virtual mechanisms are independent modules that may be loaded or not, considering the task that has to be achieved. Once a virtual mechanism is loaded, any number of instances can be created and parameterized via TaoLib functions. Parameters include virtual bounds, speed limits, or force specification along the virtual mechanism degrees of freedom (DOF).

- By connecting TAO2000 to a physical simulation engine such as XDE (eXtended Dynamical Engine) developed 


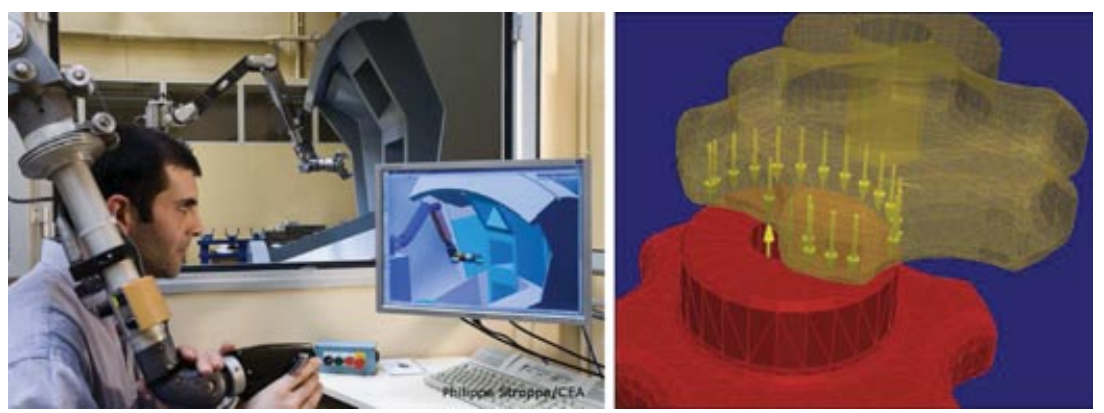

Figure 3. CEA LIST 3D robotics supervisor (left); multiple-contact-point detection with XDE (right).

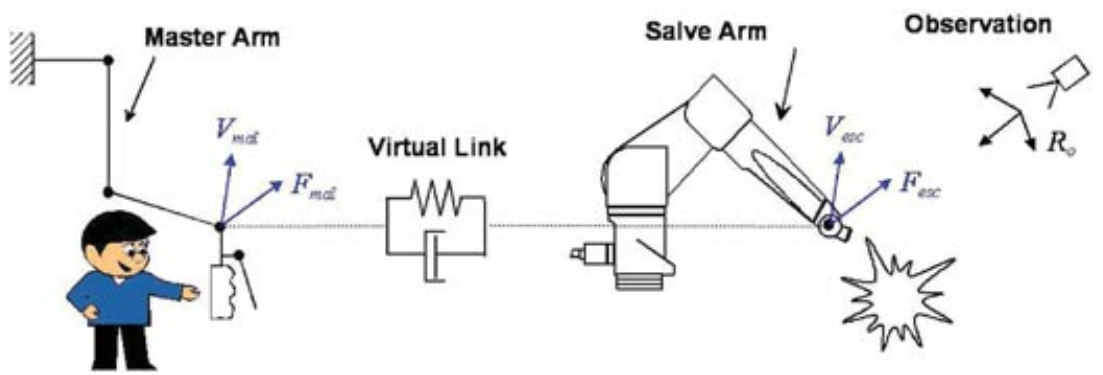

Figure 4. TAO2000 Cartesian bilateral coupling principle.

at CEA LIST. Once a fast connection is established, realtime collision detection with complex objects is available (Merlhiot, 2001)(see Figure 3) and allows avoidance of unwanted collision with the real environment. As with local mechanisms, the master arm and the slave arm are stopped by the virtual constraints, and thus the operator feels a real force feedback when contacting the virtual world. The CEA LIST 3D Graphical Supervisor called MagritteWorks, which implements the XDE library, is used in mission preparation and supervision for TAO2000 V2 systems (David, Russotto, Simoes, \& Measson, 2011; Leroux, Guerrand, Leroy, Measson, Boukarri, 2004) (see Figure 3).

By combining all these modes, the operator may easily achieve complex tasks, such as brushing a pipe using a manipulator mounted on a mobile platform. The operation may be done using a fully manual force-feedback mode or with a predefined trajectory, the operator controlling only the force against the pipe.

To facilitate the operator manipulation, some other specific teleoperation features are also provided, such as load compensation (66 kg for one roller), force and position scale factor control, observation frame modification (for easier manipulation with a camera view), load identification, camera frame identification, and plane's frame identification.

\subsection{TAO2000 Teleoperation Control Law Specifications $^{2}$}

A teleoperation system is composed of an operator, a master manipulator, a bilateral connection, a slave manipulator, and an unknown environment. As all these components must steadily work together, the TAO2000 teleoperation controller was designed based on a passivity approach (Anderson, 1989; Andriot, Dudragne, Fournier, \& Vuillemey, 1990). The goal of passivity control law design is to ensure that the system with its controller, if passive, will stay stable when contacting any passive environment with any human operator (a human operator can be considered as a passive environment with varying impedance (Dolan, Friedman, \& Nagurka, 1993). For that purpose, the TAO2000 bilateral connection drew from the obviously passive wall-tranmission steel wires of mechanical telemanipulators. Thus, the TAO2000 bilateral connection principle between mechanisms can be easily understood (see Figure 4) as emulating a six-dimensional (6D) mechanical spring and damper.

\footnotetext{
${ }^{2}$ To facilitate their integration and deployment, teleoperation systems will be specified to meet performance criteria and interfaces will be established based on the ISO workgroup "WG 24-Remote Handling" work. To be involved in this normative project, please contact philippe.garrec@cea.fr.
} 


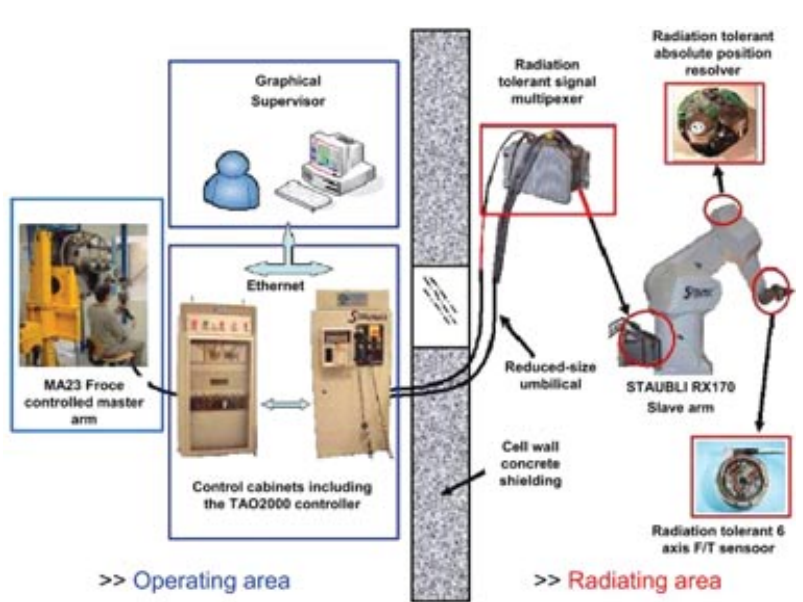

Figure 5. Hardware architecture of a Stäubli ${ }^{\mathrm{TM}} \mathrm{RX}$-based AREVA CAT system.

Using this control law, ideal transparency with a perfect transmission of forces and displacements between the master and the slave, could be achieved if both the master and the slave are perfectly backdrivable with no static balancing, friction, or inertia resulting forces. Unfortunately, manipulators (in particular industrial robots) exhibit disturbances such as joint friction, motor cogging, inertial forces, backlash, and flexibility, located in either their actuators, their transmissions, or their structure. These disturbances have a negative impact on the force resolution and lead to difficulties in executing well-defined slow motion and thus accurate force feedback. However, in the case of high friction level and inertia, accurate joint torque control can significantly increase force transparency (Geffard, Andriot, \& Morel, 2000; Williams \& Khatib, 1995). In the case of manipulators unequipped with joint torque sensors, such as the Stäubli ${ }^{\mathrm{TM}} \mathrm{RX}$ robots, an external solution must be implemented. Our choice has been to mount a rad-hard, sixaxis force/torque sensor at their end effector (see Figure 5). It measures the whole wrench at the wrist, thus allowing estimation of the joint torque and improvement of the slave backdrivability. This in turn results in an improved transparency of the whole teleoperation system.

\section{DEDICATED AND STANDARD SLAVE ROBOTS USED AT THE AREVA NC FACILITIES WITH TAO2000}

\subsection{Stäubli ${ }^{\mathrm{TM}} \mathrm{RX}$ Family Robot Rad-Hardening Developments}

The $R \& D$ for adapting industrial robots to remote handling requirements has been carried out by CEA LIST based on AREVA specifications: high reliability, radiation resistance (up to at least $10 \mathrm{kGy}$ ), decontamination potential, radiation-tolerant electronics components and sensors integration, and remote operation system with advanced functions, such as master/slave force-feedback control or
Table I. Stäubli ${ }^{\mathrm{TM}} \mathrm{RX}$ robot specifications.

\begin{tabular}{lcccc}
\hline L = Long) & nb axis & $\begin{array}{c}\text { Payload } \\
\text { max }(\mathrm{kg})\end{array}$ & $\begin{array}{c}\text { Work space } \\
\text { radius }(\mathrm{mm})\end{array}$ & $\begin{array}{c}\text { Repeatability } \\
(\mathrm{mm})\end{array}$ \\
\hline RX90L & 6 & 9 & 1,185 & 0.025 \\
RX130L & 6 & 15 & 1,660 & 0.035 \\
RX170HP & 6 & 65 & 1,835 & 0.04 \\
\hline
\end{tabular}

robotic path planning. This approach allows AREVA to benefit from optimized investment costs (cost of an industrial robots vs cost of a specific robot), as well as high reliability and maintainability of its remote handling equipment. (robustness of industrial robots). As of today, AREVA owns a complete range of industrial robots for remote operation (RX90, RX130, RX170; see Table I) which can be adapted quickly to any kind of intervention. The Stäubli ${ }^{\mathrm{TM}}$ RX robot family has been selected due to their adaptability to the specifications of nuclear manipulators. They particularly provide a high-reliability, waterproof, closed mechanical structure, easy to decontaminate, and a radiation tolerance up to 10-kGy integrated dose at low cost.

MECACHIMIE has integrated this new remote handling system with the assistance of the CEA LIST. The system includes several components, as shown in Figure 5: a Stäubli ${ }^{\mathrm{TM}} \mathrm{RX170}$ robot used as the slave arm, a sixaxis force/torque (F/T) sensor (ATI Automation radiationtolerant version), a radiation-tolerant, high-speed signal multiplexer that replaces the stiff and large robot's umbilical, a force-feedback control system dedicated to computeraided teleoperation, and a MA23 (mechanically backdrivable) force-controlled master arm.

The six-axis F/T sensor necessary to force-feedback control is mounted between the robot end effector and the gripper (also provided with force-feedback feature). The electronic multiplexer integrated at the base of the robot (in the hot cell) multiplexes all the data signals of the robot's internal sensors, the F/T sensor, and the gripper. All these digitalized data are transmitted to the demultiplixer located on the cold side via a single line, thus reducing the ombilical from 100 connection points to lower than 30 connection points. The system connection could have been therefore realized with only two small electrical plugs (standard plugs used in nuclear facilities) going through the engineered penetrations (36-mm diameter) in the cell walls. The electronic multiplexer part located in the hot cell has been qualified to be radiation tolerant up to a $10-\mathrm{kGy}$ integrated dose and 100-Gy/h flow rate. The global communication delay, for all signals, has been evaluated to be less than $52 \mu$ s with a $8-\mathrm{MHz}$ rate clock. Nevertheless, some Stäubli ${ }^{\mathrm{TM}}$ inverter gains have to be lightly modified in order to cope with this delay.

The performances obtained using Stäubli ${ }^{\mathrm{TM}} \mathrm{RX}$ robots in remote operations with force feedback have been validated, allowing safe remote high-precision tasks with 

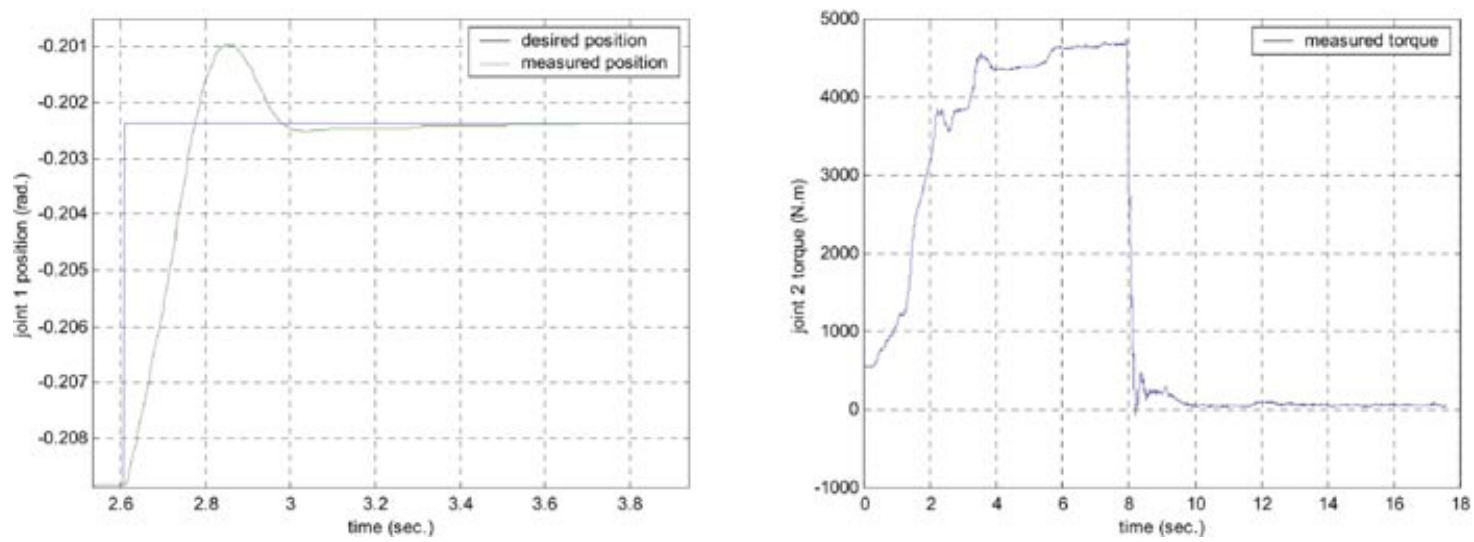

Figure 6. RX170: Joint 1 position step response in inertia max with 650-N payload (left) and joint 2 measured torque applying an effort on the environment (right).

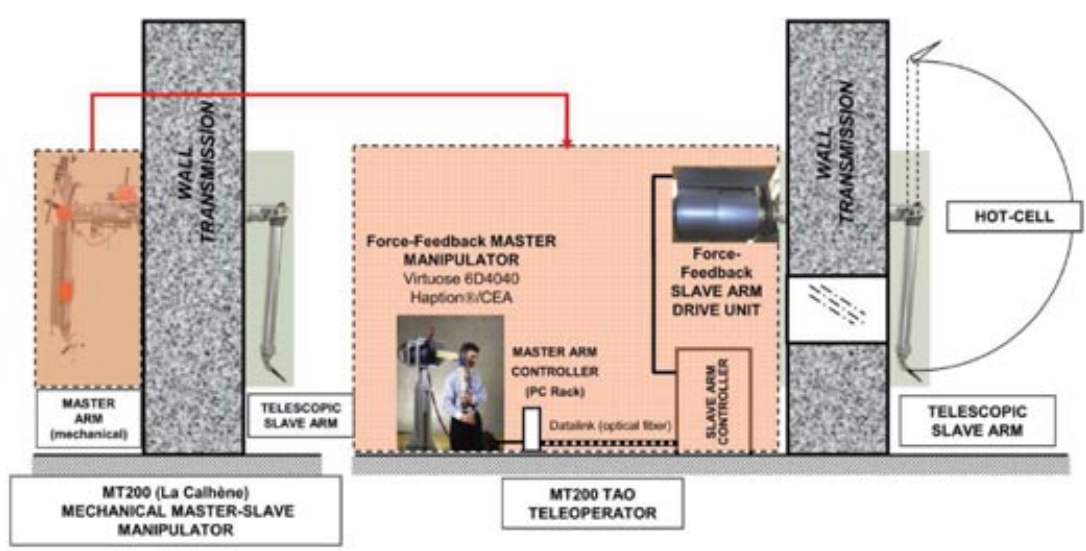

Figure 7. Form MT200 telemanipulator to MT200 TAO telerobotic system.

payloads far heavier than those encountered in manufacturing robotic applications. For example, it has been found by MECACHIMIE that a payload up to $1,000 \mathrm{~N}$ can be handled by a Stäubli ${ }^{\mathrm{TM}}$ RX170 robot in some conditions, and as is shown on Figure 6 (right) it can apply much more in some joint configurations. The performances obtained in robotic mode have been validated and can be compared with the performance obtained with the standard Stäubli ${ }^{\mathrm{TM}}$ controller.

\subsection{MT200 TAO: A Wall-Transmission Manipulator Adaptation}

\subsubsection{Specification and Design}

The MT200 TAO system is also the result of the cooperation between the Interactive Robotics Unit of CEA LIST and AREVA. It was designed to advantageously replace the MT200, a conventional, three-part through-wall, telescopic (MSM) produced by La Calhène ${ }^{\mathrm{TM}}$.
The main goals of this new system were to guarantee similar or better performances than the original MT200 telemanipulator, to increase working volume allowing ceiling access, to improve workstation ergonomics of the existing MT200 telemanipulator, to allow the operator to move away from the controlled zone in certain workstations potentially exposed to contamination or high radiation rate, to ensure safety for difficult tasks and reduce operator fatigue when located within the control zone, and to allow playback of some repetitive tasks that do not require force feedback (robotic mode).

The original cable-driven slave arm is driven by an actuator unit fitted on the wall transmission and is actually replacing the original master module (see Figures 7-9). It can be fitted to any wall transmission model equipped with any type of telescopic slave arm produced by this constructor. The master arm used is the electrical, force-feedback Virtuose 6D/4040 a compact model constructed by Haption based on CEA LIST patented technology (ball screw and 


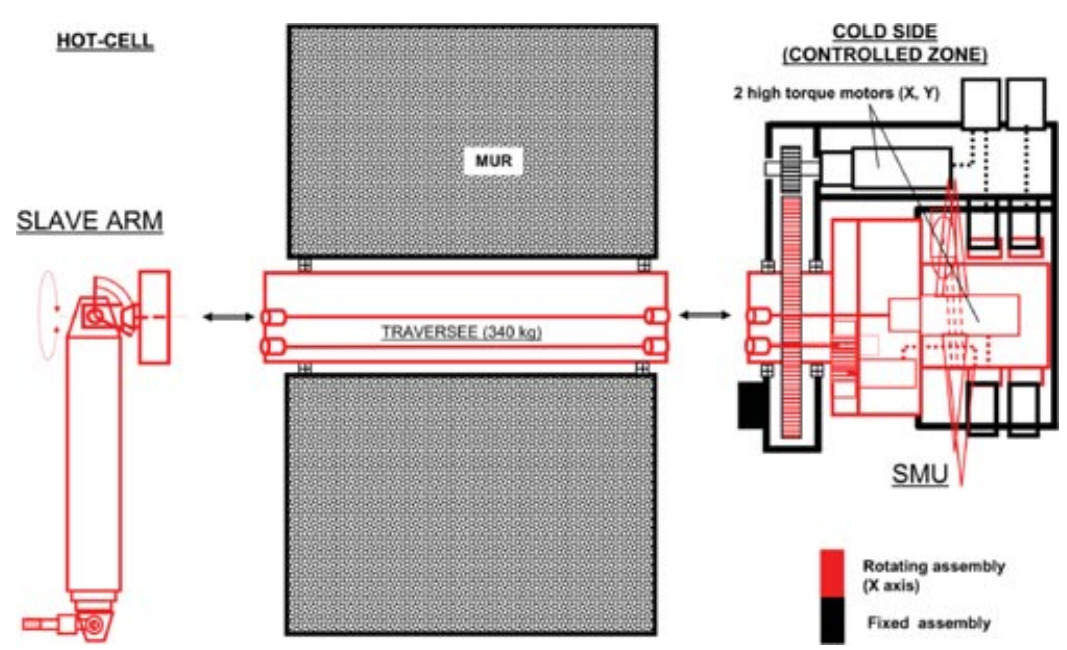

Figure 8. MT200 TAO mechanical connection/deconnection of the slave system.
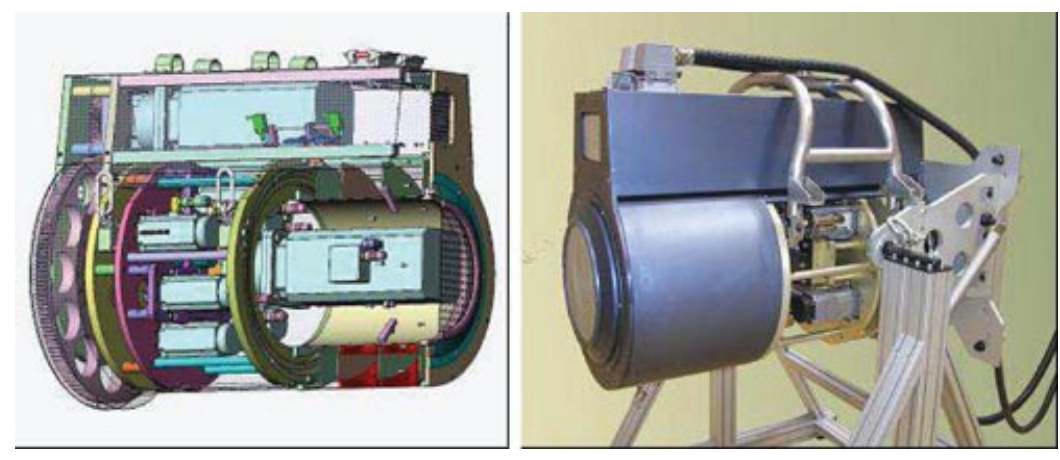

Figure 9. MT200 TAO slave actuator unit.

cables). It can exert a continuous effort of approximately 40 $\mathrm{N}$ for an average friction of $2 \mathrm{~N}$.

\subsubsection{Slave Arm Actuator Unit (SAU)}

The first requirement of a MSM is its ability to transfer an effort applied at its gripper toward the handle hold by the operator with a high fidelity. This can be translated in the concept of linear force transmission. Unfortunately, as Figure 10 (left) shows, instead of a theoretical slope $i$ (velocity ratio), a mechanical transmission presents two different torque transfer slopes $\rho_{M} i$ and $\rho_{R}^{-1} i$, depending on the sense of energy transfer (motoring or regenerating). In addition, both laws present an offset corresponding to the no-load friction of the transmission (or thresholds). Figure 10 (right) summarizes these fundamental concepts and clearly expresses the real transfer factor (energetic efficiency).

There are two major ways for linearization: the first is to minimize the offset and maximize the factors $\rho_{M}$ and $\rho_{R}$ (called asymptotic or maximum efficiency) by design (alike servomanipulator/electrical MSM design), and the second is to implement a force retroaction between the output and input, for example by adding a joint torque sensor. To ensure high reliability, reduce the complexity of the fabrication of the SAU, and avoid the inconvenience of calibration procedures, we opted for an optimization of the design. As a target objective, we chose the indicative values given in Vertut and Coiffet (1986) for MSM: 2\% for a rotative joint and $10 \%$ for a telescopic joint. It should be noticed, however, that because both master and slave are coupled, each manipulator should individually present even better performances.

In our case these choices have led to the highest motor torque available and consequently the lowest reduction ratios, disregarding the relative inconveniency of a lower stiffness. This option is justified in a teleoperation context in which the operator compensates the flexibility of the system by observing the end effector. The cumulated continuous torque required to generate the payload and balance the arm gravity on the two first joints is particularly high. This is due to a high extension, a hemispherical working 

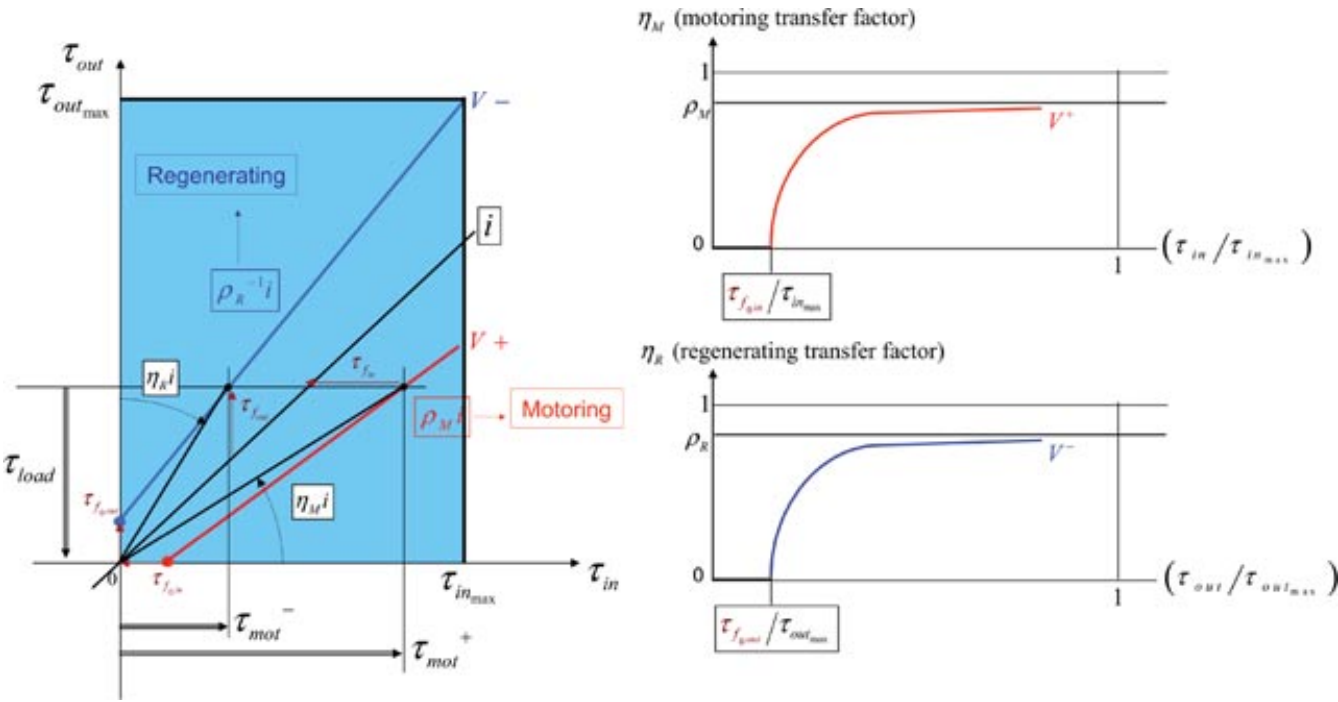

Figure 10. Transmission effort transfert diagram.

volume, and the absence of counterweight. As a reference, for the "1760" version of the MT200 slave arm extending up to $4 \mathrm{~m}$, the maximum gravity torque reaches half of the payload torque. For these reasons, we selected hightorque brushless motors and their associated servoamplifiers (Parvex components). On the two first joints, the size of the selected motors is large enough to allow forced ventilation. This feature enables a $40 \%$ drop in the reduction ratio compared to the naturally cooled version of the same motor and consequently a significant reduction in the motor hysteresis (mechanically equivalent to a dry friction torque) contribution in the relative thresholds.

The torque transfer diagram identified with a "1390" slave arm model for the first joint $(\mathrm{X})$ is shown in Figure 11 (left). Figure 11 (right) shows its extrapolated model.
The velocity ratios of the SAU (shown in Table II) are globally closer to those encountered on master arms than those encountered on slave arms, confirming the EMSM design philosophy.

The hemispherical working volume led to assignment of a 1.5 turn of freedom on the $X$ axis and keeping it integrated inside the SAU housing. It uses cable chains with dual flexibility (countercurvature) arranged according to a known kinematic principle found in the industry (example IGUS catalog). The center of the countercurvature moves according to an epicycloidal speed reducer allowing the mobile point of the chain to travel more than one turn (see Figure 12). This design has been adapted to work in the vertical plane and optimized to limit its contribution to the $X$ friction threshold.
Wentified torque transfer diagram - X joirt (low speed)

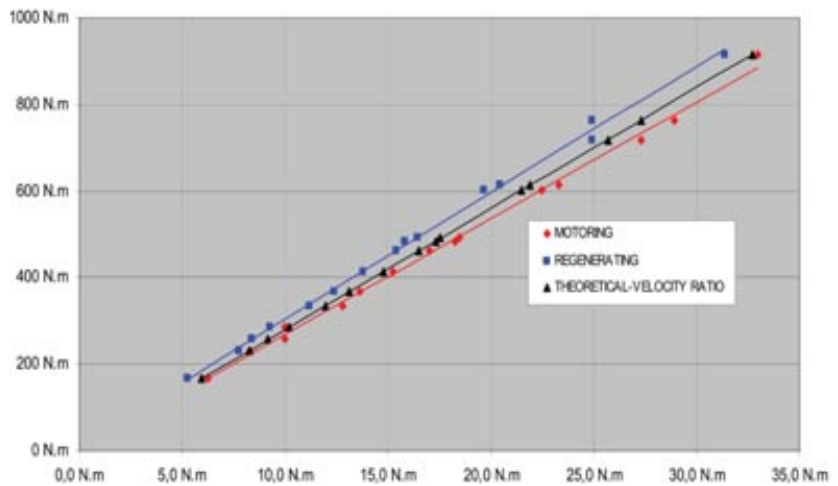

Torque transfer model - X joint (low speed)

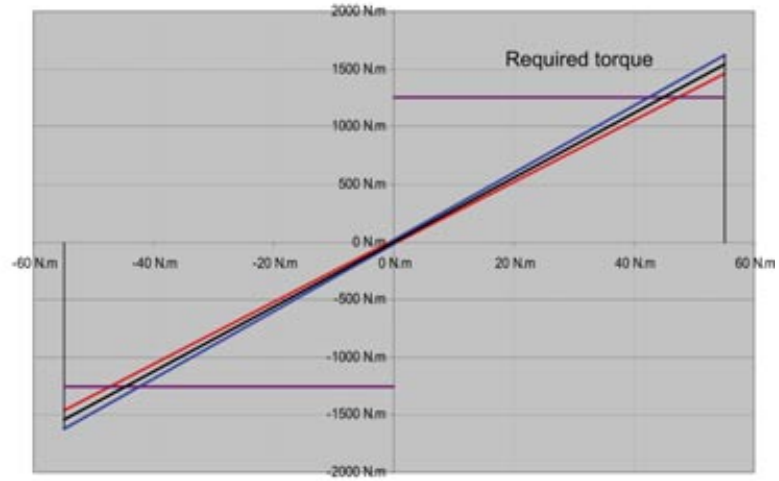

Figure 11. Joint 1 torque transfert diagram: Measures (left) and extrapolation (right). 

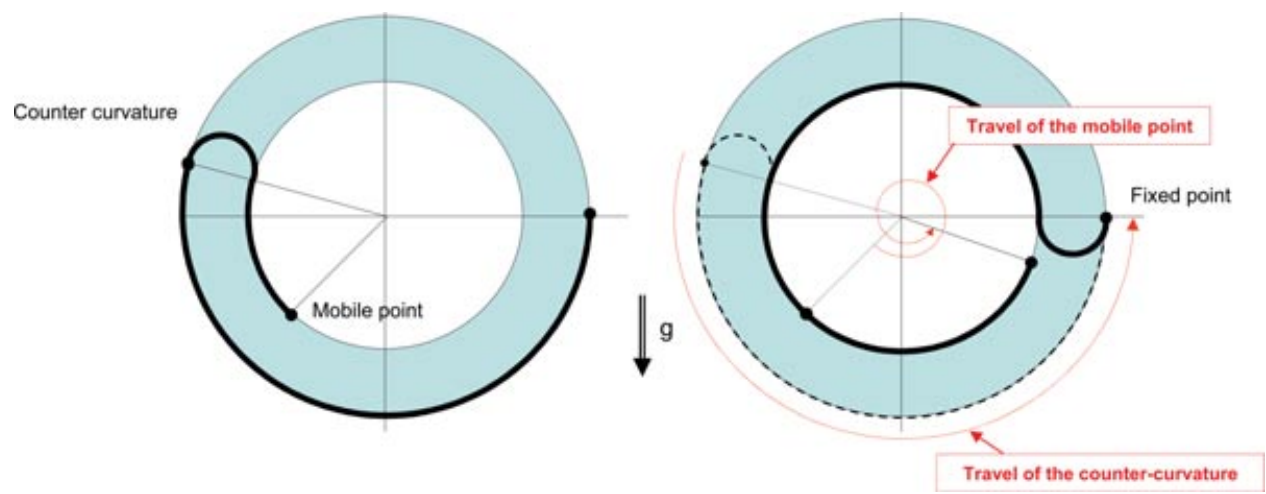

Figure 12. SAU cable mobile chain principle.

Table II. SAU velocity ratios.

\begin{tabular}{lccl}
$\begin{array}{l}\text { Joint } \\
\text { number }\end{array}$ & $\begin{array}{c}\text { Joint } \\
\text { name }\end{array}$ & $\begin{array}{c}\text { Velocity ratio } \\
(\text { rad.rad }\end{array}$ & \\
\hline 1 & X & 28 & Wall-transmission rotation \\
2 & Y & 28 & Arm flexion \\
3 & Zelec & 1,178 & Arm extension \\
4 & Zman & 67 & Arm extension \\
5 & AZ & 11 & Arm rotation \\
6 & EP & 7.4 & Gripper elevation (flexion) \\
7 & RP & 3.3 & Gripper rotation \\
8 & SP & 108 & Gripper \\
\hline
\end{tabular}

As general guidelines, we also wished as much as possible to minimize the backlash and favor commercially available components and known reliable mounting principles and procedures.

There were also some more detailed user specifications to be taken into account, such as the fact that motorization design has to be adaptable to any kind of similar disconnectable manipulator (transmission through the wall by ro- tative shafts, that the motorization unit must be compatible with all versions of the same manufacturer (slave arm length parameter), and that the motorization unit can operate with a second adjacent mechanical manipulator or a second motorization unit (operate with a left/right hand or two operators). SAU main technological characteristics are summarized in Table III, and a more detailed description of this system can be found in reference (Garrec et al., 2005).

\subsubsection{Master Arm}

The Virtuose 6D4040 Haption $^{\mathrm{TM}}$ is as product issued from CEA technology. Its patented actuators combine a reversible ballscrew and a cable (a concept named SCS, for screw and cable system)(see Figure 13). Although its performances in working volume, force, and friction are similar to those of pioneering models such as Model $\mathrm{M}$ (ANL/CRL), Mascot (ENEA/Ansaldo), MA23 (CEA/La Calhne), or EMSM 2 (KFK/FZK), its weight and dimensions, as well as its cost, have been significantly reduced. Main specifications of the Virtuose 6D4040 are presented in Table IV.

Table III. SAU main technological characteristics.

Characteristic

Description

\begin{tabular}{ll}
\hline $\begin{array}{l}\text { Motors } \\
\text { Number }\end{array}$ & 8 (2 are forced ventilated) \\
Type & Autosynchronous (“brushless”) NdFeB magnets, three-phase 400-V supply \\
Mechanical transmissions & \\
Joint X & Epicyclic (planetary) speed reducer and spur gear (hemispherical working volume) \\
Joint $Y$ & Epicyclic (planetary) speed reducer (idem than $X)$ \\
Other joints & Synchronous belt (backlash free, low noise) \\
Position sensors & Resolvers/absolute position by counter with backup \\
Weight & $360 \mathrm{~kg}$ \\
Ombilical & Fully integrated; angular freedom 1.5 turn (540 deg) \\
\hline
\end{tabular}



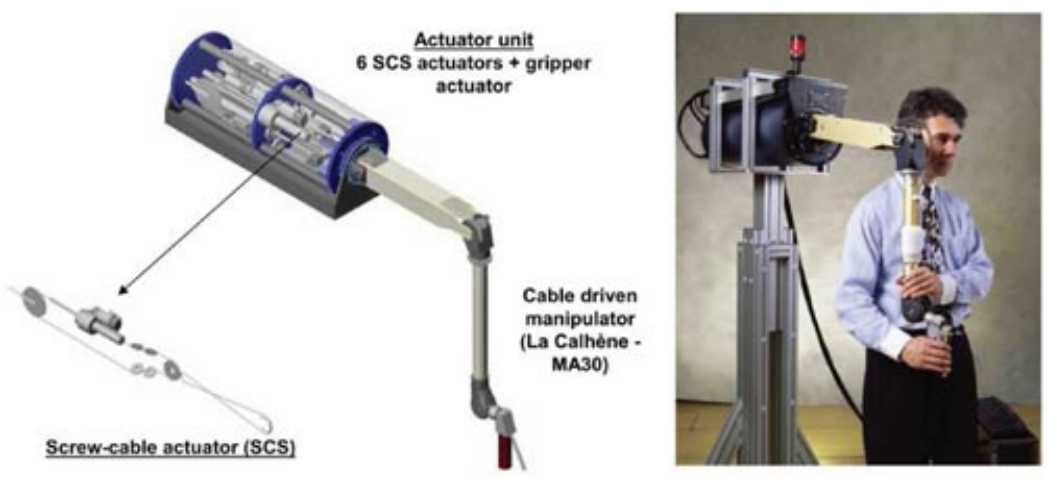

Figure 13. Virtuose 6D 40-40 (CEA/Haption ${ }^{\mathrm{TM}}$ ) force feedback master arm: general kinematics and actuator (SCS).

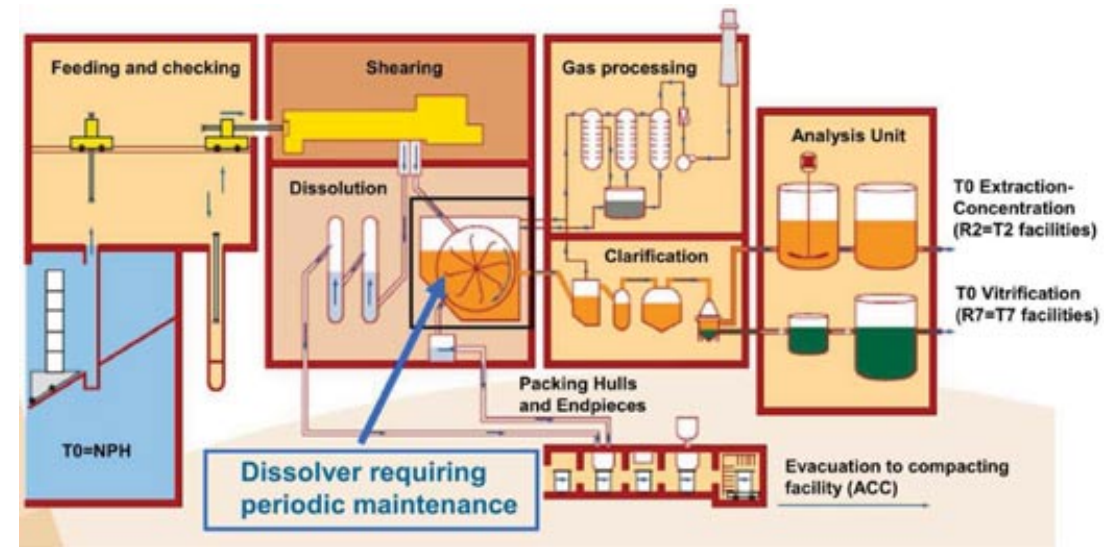

Figure 14. Shearing and dissolution facility at AREVA-La Hague plant.

Table IV. Main specifications of the force feedback master arm Virtuose 6D4040 Haption ${ }^{\mathrm{TM}}$.

\begin{tabular}{ll} 
Characteristic & \multicolumn{1}{c}{ Description } \\
\hline $\begin{array}{l}\text { Motor } \\
\text { Transmission }\end{array}$ & $\begin{array}{c}\text { Maxon ironless dc } \\
\text { Synchronous belt/reversible } \\
\text { ball-screw/cable } \\
\text { transmission }\end{array}$ \\
Gripper handle & $\begin{array}{c}\text { Harmonic-drive speed } \\
\text { reducer/cable transmission }\end{array}$ \\
Translation force feedback & $40 \mathrm{~N}$ continuous \\
Rotation force feedback & $2 \mathrm{~N} \cdot \mathrm{m}$ continuous \\
No load friction (translation) & $2 \mathrm{~N}$ (average) \\
Total mass of the arm & $<40 \mathrm{~kg}$ \\
\hline
\end{tabular}

\section{TELEMAINTENANCE OPERATIONS AT THE AREVA NC-LA HAGUE FACILITY USING INDUSTRIAL ROBOTS}

The purposes of these maintenance operations were to remove the rollers of the nuclear fuel dissolver wheel and to clean the interbucket spaces of the wheel of the dissolver. There are three similar dissolution cells at the La Hague nu- clear plant. The first operation has already been carried out successfully in two dissolution cells (first detailed in Piolain, Geffard, \& Coudray, 2005), and the second operation was recently validated on a mock-up.

\subsection{Environment}

The shearing and dissolution process is shown on Figure 14. Fuel is cut into rods approximately $35 \mathrm{~mm}$ long. These "hulls" contain the used fuel nuclear material. They fall by gravity into one bucket of the dissolver wheel, where nuclear material is dissolved by hot nitric acid.

The dissolver is located in the dissolution cell. It is composed of a flat tank filled with hot concentrated nitric acid and a 12-bucket dissolution wheel. Periodically, the wheel of the dissolver is raised, with its cover in the high activity maintenance cell located above the dissolution cell.

\subsection{Wheel Roller Maintenance}

The dissolver wheel rolls on eight rollers fixed to a supporting frame. The rollers must be replaced every 5 years within the framework of preventive maintenance. The roller is 


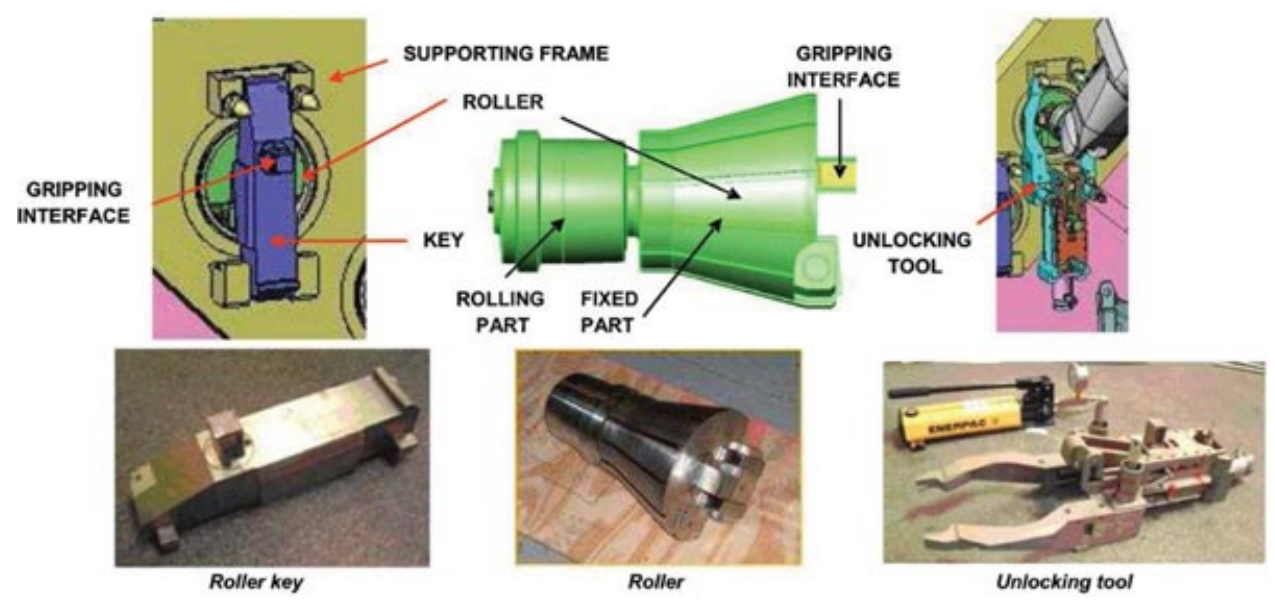

Figure 15. Principal mechanical tools and roller parts.
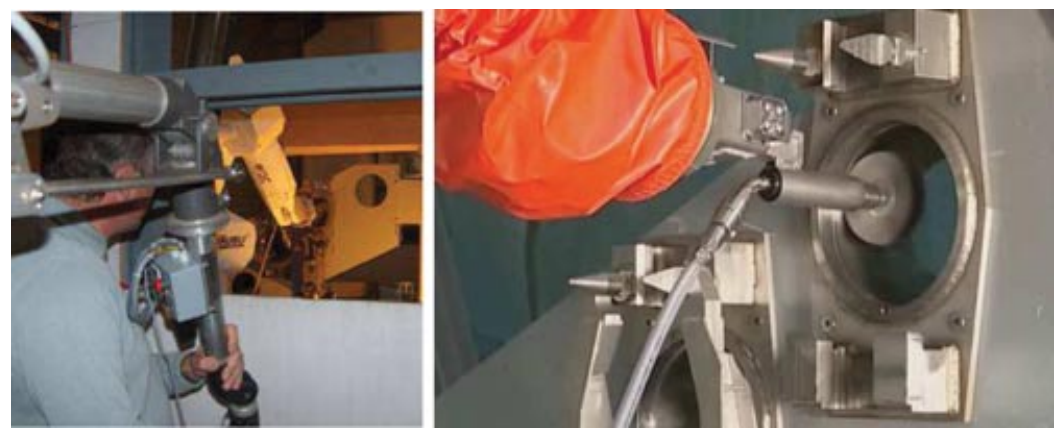

Figure 16. Brushing task on the mock-up.

composed of a rolling part and a fixed part, and each roller is locked by a key that jams the roller to the supporting frame. Unlocking is carried out by a special tool. The key, the special unlocking tool, and the roller are equipped with specific handles to be gripped by the manipulator. The roller, key, and unlocking tool weights are respectively: 660,360 , and $560 \mathrm{~N}$ (see Figure 15), and the center of gravity of the roller is located at $170 \mathrm{~mm}$ from the "handling cask" (gripping handle present on each manipulable object or tool).

The maintenance cell is equipped with wall-mounted MT200 mechanical master-slave manipulators. Unfortunately, these manipulators do not have the payload capacity required for these operations. Therefore, new powerful remote handling equipments had to be introduced inside the cell.

The selected CAT system is based on the Stäubli ${ }^{\mathrm{TM}}$ RX170 robot (see Section 3.1.; Figure 5). Moreover, for the roller-changing operation, MECACHIMIE modified the inverters capacities in order to enhance RX170's nominal payload. Almost all TAO2000 control modes have been used successively during this operation (more details can be found in (Piolain et al., 2005): predefined trajectory to drop off the rollers and the tools, Cartesian force-feedback tele- operation mode for unlocking and to extract the roller, and mixed position/force mode during the hole cleaning (see Figure 16).

The whole operation, for one hot cell, including the CAT system settling and removing and the changing of all the wheel rollers, took 10 days (operating $10 \mathrm{~h} /$ day).

By the end of December 2005, the first operation took place at the T1 facility (dissolution cell of the UP3 plant). This operation lasted 2 weeks as had been planned, compared to the several weeks that were formerly necessary when the operation was carried out with conventional remote handling equipment without force-feedback. At the end of the operation, the RX170 robot was disconnected and stored in another cell near the dissolution cell.

In December 2007, the same intervention was planned on the R1 facility (dissolution cell of the UP2 800 plant). The RX170 used in 2005 was put back into service within 1 week. At MECACHIMIE, a mock-up was set up using similar equipment in order to train new operators and to prepare the maintenance task. At the beginning of February 2008 , the changing of all rollers took place during 2 weeks. At the end of this operation, the dissolver was brought back into service. 

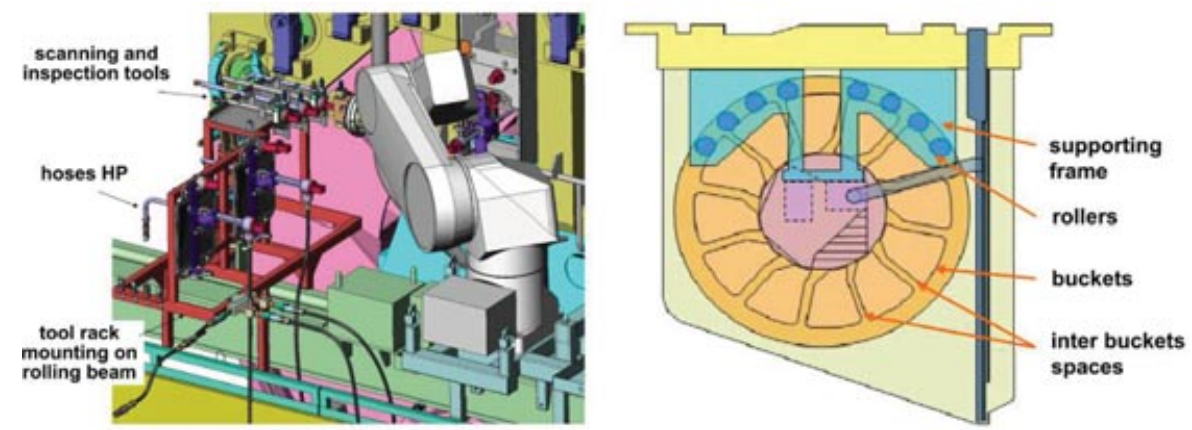

Figure 17. The tool rack (left). The dissolver wheel and its buckets (right).

In December 2010, a third operation was realized for a second time at the T1 facility. And since that, this maintenance operation became a standard intervention in the AREVA NC-La Hague recycling plant.

\subsection{The Clean-Up Intervention}

The wheel is composed of buckets connected two-two by a balance weight (Figure 17). These buckets are comparable to sieves, with several perforated faces where the holes are approximately $1 \mathrm{~mm}$ in diameter (Figure 18).

This maintenance operation consists of the cleanup of the interbucket spaces (Figure 17) using a high-pressure water jet. The purpose of this cleanup is to remove the deposit in order to maintain the best process efficiency. Access to the interbucket spaces by a high-pressure hose is made particularly difficult due to the balance weights. This operation requires an accurate automatic system ensuring that each hole is reached by the high-pressure water jet and minimizing the volume of generated effluents. Thanks to the success of the previous maintenance operations (see Section 4.2), AREVA has decided to use the same equipment for the cleanup operation of the interbucket space.

The Stäubli ${ }^{\mathrm{TM}}$ RX170-based CAT system was thus selected for this second maintenance operation. During this intervention, the robot first accesses the interbucket spaces and detects several contact points on the bucket faces using the available end-effector force/torque sensor. Then the controler calculates the plan equation and uses it in order to compute the cleanup trajectories. The high-pressure water jet is launched only when the robot starts to move. For each bucket the cycle ended with a cleanup quality check.

For this operation, MECACHIMIE designed and built several specific pieces, such as a full-size mock-up of the environment (Figure 18), and a containment box (Figure 18) avoiding the dispersion of the contamination in the maintenance cell. This box is placed ahead of the interbucket spaces. It allows directing the effluent up to a flow system between the wheel and the tank of the dissolver. This box has one opening on each side of the mass of balancing in order to allow the tools access. MECACHIMIE also built scan- ning tools in order to reference the positions of the bucket in the robot frame (Figure 18), several hoses for the highpressure water process (Figure 18), inspection tools in order to control the efficiency of the cleaning (Figure 18), and, obviously a tool rack for the storage of the tools within the robot range (Figure 17).

Tool choice and approach operations are performed using the force feedback feature of this system (Cartesian bilateral coupling control mode, see Section 2.3.). All cleanup operations with the high-pressure water are achieved with preprogrammed optimized trajectories in order to go past every interbucket hole with a constant speed and to reduce the volume of generated effluents. As each interbucket space is divided into several plans, each plan is the object of a specific automated cycle: plan identification, cleanup, and checking.

This remote task implements several CAT features, including force feedback control and preprogrammed automatic cycles on complex refined trajectories. The preparation of this intervention was realized and qualified at the end of 2008. The intervention itself was achieved in February 2011. Feedback of this operation has not yet been
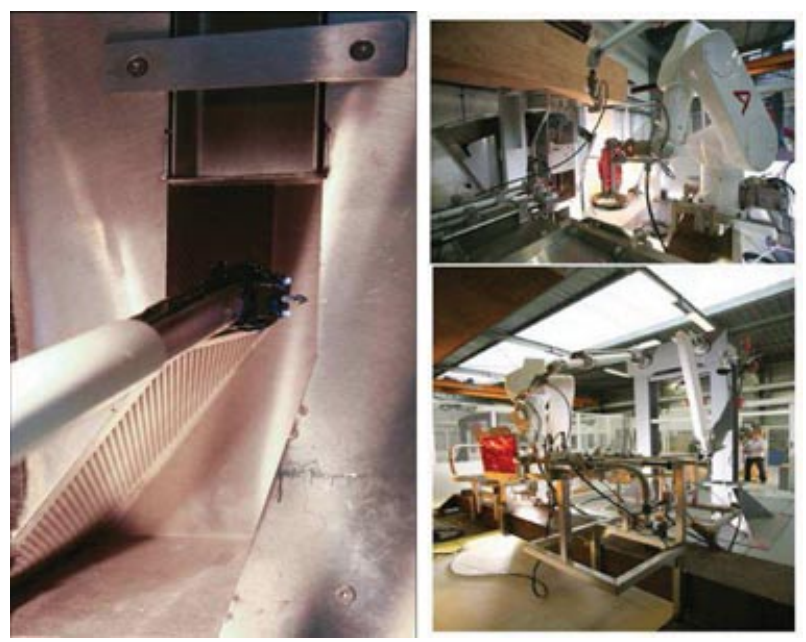

Figure 18. Mock-up of the interbucket application. 

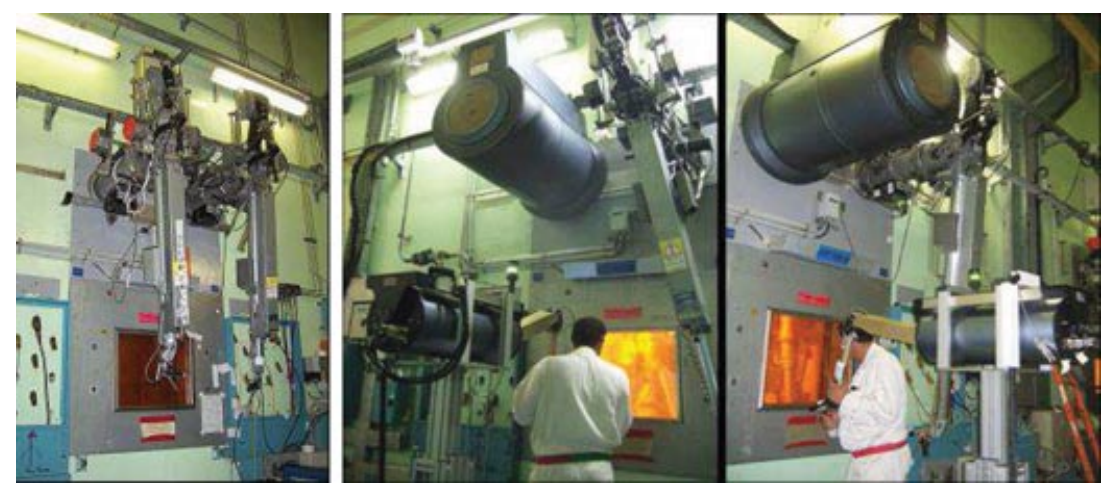

Figure 19. Virtuose 6D 40-40 [a conventional workstation (left)], and a mixed workstation equipped with the new MT200 TAO telerobot and a standard MT200 MSM (right).

completely analyzed. It is therefore too early to discuss it in this paper.

\section{MT200 TAO OPERATIONS FEEDBACK IN AREVA NC-LA HAGUE RECYCLING PLANT}

AREVA NC has recently put into service the MT200 TAO telerobot in the La Hague recycling plant. This system has been functionally replacing a conventional three-part (including wall transmission) mechanical MSM since September 3, 2010. The workstation has been selected for its highly demanding type of work. The workstation is equipped with a radiation shielding wide window. The MT200 TAO telerobot is installed on the left through-wall tube, whereas the right one is fitted with a standard MT200 MSM (Figure 19).

The operators were trained in advance on a cold mockup for a few days, and an ergonomic follow-up of the working conditions was implemented by the medical service of the plant. The principal tasks performed on this workstation are physically demanding (straining) and consist of cleaning parts using chisels on a day-to-day basis. Feedback on the system was rapidly obtained due to this choice of task. It was also possible to record the performances of the system. An operational benefit is estimated on the production thanks to the increase in the operator's dexterity and endurance. Operators work $60 \%$ longer without fatigue and realize a standard task $20 \%$ faster compared with the use of conventional MSM. Other tasks have been performed by the telerobot, such as the replacement and cleaning of the internal face of the window (called here the "alpha frame") with the same conclusions.

These results reveal the efficiency of computer assistance for teleoperated daily tasks. New functions such as Cartesian indexing, automatic telescopic indexing, independently adjustable position and force scale factors, automatic bolting function, and also the perfect balance of the telerobot inside the whole work space are the main reasons for this progress. The level of force feedback sensitivity of the telerobot has allowed operators to successfully engage threads.

Moreover, due to torque limitations and the previously mentioned computer assistance, the lifetime of the cabledriven slave arm has been drastically increased. Considering the chiseling task, we estimated that the lifetime has been increased at least by a factor of 4 (based on a 9-month experience). As of today the system worked for $400 \mathrm{~h}$ in master-slave mode (force feedback) without failure, and was still functional when the validation tests were stopped on June 16, 2011. The only interruption of service corresponded to safety margin detection (speed error) and relative position encoder calibration.

The general impression of operators is positive concerning the comfort and the decrease of fatigue in continuous work conditions. With regard to ergonomics, the work position is advantageous because the operator is always well positioned, even when the slave arm is far removed from the window axis. As a result, the accuracy of the movements is greatly increased.

The positive feedback obtained during the year 2010 enables us to conclude that the concept of force feedback teleoperation using a dissimilar master and slave arm, in terms of both kinematics and working volume, is valid. All operators are globally satisfied and wish to extend its use on their workstation. The evaluation will be continued with other tasks such as the maintenance of hot-cell, lifting equipment, which requires working in the upper part of the cell, an area that is both out of view for the operator and out of reach for a conventional MSM.

\section{CONCLUSIONS AND PERSPECTIVES}

Remote robotics or telerobotics, the combination of robotics and remote operation, applied in the nuclear industry is an instrument of continuous progress and sustainable development. Lessons learned of the use of telerobotics means at the AREVA-La Hague reprocessing plant are multiple. First, telerobotics is an evolution of operator work by allowing operators to work in a remote comfortable 
environment, which furthermore reduces their integrated dose thanks to their distance from the radiating zone. Concerning the task, the risks are mitigated due to the force feedback feature and the automation of complex or repetitive trajectories. The volume of waste is also reduced as inferred by the safety of the operations and the reliability of the intervention system. Finally, another argument in favor of such a system is the economical sustainability of today's industrial robots.

The Stäubli ${ }^{\mathrm{TM}} \mathrm{TAO}$ system is used as a reference remote handling system for the design of new nuclear installations, as well as for the dismantling of old nuclear installations. MECACHIMIE is currently upgrading the Stäubli ${ }^{\mathrm{TM}}$ TAO system with the last Stäubli ${ }^{\mathrm{TM}}$ robot generation (RX160 and TX200) in order to ensure the continuation of industrial robot-based telerobotics at the AREVA NC-La Hague facilities. These systems are also expected to be used for a wide range of operations.

Concerning the MT200 TAO system, the first successful trials in a hot cell at the AREVA NC-La Hague recycling plant demonstrate that the concept of force feedback teleoperation using a dissimilar master and slave arm, in terms of both kinematics and working volume, is valid. All operators are globally satisfied and wish to use this system in other operations. This new system can already replace a conventional MSM on certain workstations with a better time efficiency. Moreover, the limitations and assistances provided by the computer-assisted control have a positive effect on the lifetime of the original cable-driven slave arm. In spite of the confirmation of these results, another more robust slave arm has been designed by CEA LIST and AREVA. This arm, named TERMAN, is expected to be built within 2 years. It will have a similar payload (200 $\mathrm{N})$ but a significantly increased, by a factor of 10, lifetime.

\section{REFERENCES}

Anderson, R.-J. (1989). A network approach to force control in robotics and teleoperation. Ph.D. Thesis in Electrical Engineering, University of Illinois, Urbana.

Andriot, C., Dudragne, J., Fournier, R., \& Vuillemey, J. (1990, June). A generalized bilateral control applied to masterslave manipulators. In RO.MAN.SY'90, Cracovy, Poland.

Bruyninckx, H. (2001, May). Open robot control software: The Orocos project. In Proceedings of the 2001 IEEE International Conference on Robotics and Automation, ICRA 2001, Seoul, Korea (vol. 3, pp. 2523-2528).

David, O., Russotto, F.-X., Simoes, M. D. S., \& Measson, Y. (2011). Interactive anti collision in supervisory control systems for computer aided teleoperation. Industrial Journal of Robotics Research (submitted for publication).

Desbats, P., Cammoun, R., Littmann, F., Kervanoel, T. J. D., Idasiak, J., \& Andriot, C. (1999, April). Development of a new dextrous arm for telerobotic maintenance of nuclear facilities. In Proceedings of the ANS 8th Topical Meeting on Robotics and Remote Systems, Pittsburgh, PA.
Desbats, P., \& Piolain, G. (2005, December). Overview of remote handling technologies developed for inspection and maintenance of spent fuel management facilities in france. In ENC 2005, Versailles, France.

Dolan, J., Friedman, M., \& Nagurka, M. (1993). Dynamic and loaded impedance components in the maintenance of human arm posture. IEEE Transactions on Systems, Man and Cybernetics 23, 698-709.

Garrec, P., Friconneau, J., \& Louveau, F. (2004, March). Virtuose 6D: A new industrial master arm using innovative ball-screw actuators. In 35th International Symposium on Robotics, Paris-Nord-Villepinte, France.

Garrec, P., Piolain, G., Lamy-Perbal, S., \& Friconneau, J.-P. (2005, December). The telerobotics system MT200-TAO replaces mechanical telemanipulators in COGEMA/AREVA-La Hague hot cells. In ENC 2005, Versailles, France.

Geffard, F., Andriot, C., \& Morel, G. (2000, June). A comparative study of torque control using a wrist or a base force/torque sensor. In RO.MAN.SY'00, Cracovy, Poland.

Gicquel, P., Andriot, C., Coulon-Lauture, F., Measson, Y., \& Desbats, P. (2001, March). Using an industrial robot for maintenance telerobotic operations in active cells at cogema recycling plant. In ANS 9th Topical Meeting on Robotics and remote system, Seattle, WA.

Joly, L., \& Andriot, C. (1994). Imposing motion constraints to a force reflecting telerobot through realtime simulation of a virtual mechanism. In Proceedings of the IEEE International Conference on Robotics and Automation, San Diego, CA (pp. 357-362).

Leroux, C., Guerrand, M., Leroy, C., Measson, Y., \& Boukarri, B. (2004, November). Magritte: A graphic supervisor for remote handling interventions. In Proceedings of ASTRA'04, 8th ESA Workshop on Advanced Space Technologies for Robotics and Automation, Noordwijk, Netherlands.

Merlhiot, X. (2001, June-July). Extension of a time-stepping compatible contact determination method between rigid bodies to deformable models. In Proceedings of the Multibody Dynamics 2009, ECCOMAS Thematic Conference, Warsaw, Poland.

Piolain, G., Geffard, F., \& Coudray, A. (2005, December). Using an industrial robot for maintenance telerobotic operations in active cells at cogema recycling plant. In ENC 2005, Versailles, France.

Piolain, G., Geffard, F., Coudray, A., Garrec, P., Thro, J.-F., \& Perrot, Y. (2010, October). Dedicated and standard industrial robots used as force-feedback telemaintenance remote devices at the areva recycling plant. In Proceedings of 1st International Conference on Applied Robotics for the Power Industry (CARPI), Montreal, Canada.

Vertut, J., \& Coiffet, P. (1986). Teleoperation and robotics. Evolution and Development, Vol. 3A. Upper Saddle River, NJ: Prentice-Hall.

Williams, J.-D., \& Khatib, O. (1995, June). Improved force control for conventional arms using wrist-based torque feedback. In Proceedings of the International Symposium on Experimental Robotics (pp. 448-457), Standford, CA. 